\title{
Erratum to: Biomineralization capability of adherent bio-glass films prepared by magnetron sputtering
}

\author{
G. E. Stan $\cdot$ S. Pina $\cdot$ D. U. Tulyaganov
}

J. M. F. Ferreira $\cdot$ I. Pasuk $\cdot$ C. O. Morosanu

Published online: 12 March 2010

(C) Springer Science+Business Media, LLC 2010

Erratum to: J Mater Sci: Mater Med

DOI 10.1007/s10856-009-3940-9

The authors regret that during the publication of the above paper there was an error in Table 2 (column 3, row 2): 20.6 should read 30.6.

Please find the updated table reproduced below (Table 2).

Table 2 EDS chemical composition in at $\%$ calculated for the as deposited BG films

\begin{tabular}{lcrr}
\hline Element & BG2 & BG4 & BG5 \\
\hline $\mathrm{Si}$ & 30.2 & 30.6 & 31.2 \\
$\mathrm{Ca}$ & 32 & 19.8 & 26.5 \\
$\mathrm{P}$ & 2.6 & 2.8 & 3.9 \\
$\mathrm{Na}$ & 16.2 & 26.9 & 20.6 \\
$\mathrm{Mg}$ & 19 & 19.9 & 17.8 \\
\hline
\end{tabular}

C. O. Morosanu: Deceased.

The online version of the original article can be found under doi:10.1007/s10856-009-3940-9.

G. E. Stan $(\bowtie) \cdot$ I. Pasuk · C. O. Morosanu

National Institute of Materials Physics, P.O. Box MG-7,

Bucharest-Magurele, Ilfov 077125, Romania

e-mail: george_stan@infim.ro

S. Pina · D. U. Tulyaganov · J. M. F. Ferreira

Department of Ceramics and Glass Engineering, CICECO,

University of Aveiro, Aveiro, Portugal 